\title{
Fracture Toughness of an Advanced Ultrahigh-strength TRIP-aided Steel
}

\author{
Junya KOBAYASHI, ${ }^{1 *}$ Daiki INA, ${ }^{2)}$ Asahiko FUTAMURA ${ }^{3)}$ and Koh-ichi SUGIMOTO ${ }^{3)}$ \\ 1) Research Fellow of Japan Society for the Promotion of Science, Graduate Student, Shinshu University, 4-17-1 Wakasato, \\ Nagano, 380-8553 Japan. $\quad$ 2) Graduate Student, Shinshu University, 4-17-1 Wakasato, Nagano, 380-8553 Japan. \\ 3) Department of Mechanical Systems Engineering, Shinshu University, 4-17-1 Wakasato, Nagano, 380-8553 Japan.
}

(Received on July 12, 2013; accepted on December 4, 2013)

\begin{abstract}
The fracture toughness of an advanced ultrahigh-strength $0.2 \% \mathrm{C}-1.5 \% \mathrm{Si}-1.5 \% \mathrm{Mn}-1.0 \% \mathrm{Cr}-0.05 \% \mathrm{Nb}$ (in mass \%) transformation-induced plasticity (TRIP)-aided steel with a bainitic ferrite and/or martensite structure matrix was investigated for applications in automobiles, construction machines, and pressure vessels. After the steel was austenitized and isothermally transformed via heat treatment at temperatures between $200^{\circ} \mathrm{C}$ and $350^{\circ} \mathrm{C}$ below the martensite-finish temperature, it exhibited a good combination of tensile strength $(1.4 \mathrm{GPa})$ and total elongation $(15 \%)$. In addition, the steel achieved a much higher plane-strain fracture toughness $\left(K_{\mathrm{IC}}=129-154 \mathrm{MPa} \mathrm{m}^{1 / 2}\right)$ than conventional structural steel such as SCM420 steel $\left(K_{\mathrm{IC}}=\right.$ 57-63 MPa $\mathrm{m}^{1 / 2}$ ). Surprisingly, the fracture toughness was nearly the same as that of a maraging steel. Our results indicate that the high fracture toughness was associated with (1) a softened wide lath-martensite matrix with a low carbide content and carbon concentration and (2) effective plastic relaxation of localized stress concentration by the strain-induced transformation of fine metastable retained austenite in the narrow lath-martensite and retained austenite mixture, which suppresses void formation and cleavage crack initiation at the pre-crack tip.
\end{abstract}

KEY WORDS: fracture toughness; ultrahigh-strength steel; TRIP-aided steel; microstructure; retained austenite; martensite; bainitic ferrite.

\section{Introduction}

Ultrahigh-strength transformation-induced plasticity (TRIP)-aided steels with bainitic ferrite and/or martensite structure matrix ${ }^{1-3)}$ have recently been developed as thirdgeneration ultrahigh-strength cold-rolled sheets for automotive bodies. In addition, other ultrahigh-strength steels such as quench and partitioning (Q\&P) steel $^{4,5)}$ and $5-25 \% \mathrm{Mn}$ TRIP/twining-induced plasticity (TWIP) steels ${ }^{6,7)}$ were also developed. These steels possess excellent elongation, stretch-flangeability and bendability owing to the TRIP effect of metastable-retained austenite, and the steels have thus been partially used for the structural parts of automobiles. TRIP-aided steels also promise to be next-generation structural steels in the forging of mechanical parts of various machines because of their excellent impact toughness ${ }^{8,9)}$ and high notch fatigue strength ${ }^{10,11)}$ resulting from the effect of plastic relaxation on the strain-induced transformation of metastable-retained austenite of 3-10 vol\%.

If these TRIP-aided steels are to be used in higher pressure vessels and further high strength construction machines, high fracture toughness is also required. However, there has been no report on the fracture toughness of ultrahigh-strength TRIP-aided steels.

* Corresponding author: E-mail: koba@sugimotolab.shinshu-u.ac.jp DOI: http://dx.doi.org/10.2355/isijinternational.54.955
The current study investigated the fracture toughness of ultrahigh-strength TRIP-aided steels produced by isothermal transformation (IT) at different temperatures in linear and nonlinear fracture toughness tests employing acoustic emission (AE). In addition, the fracture toughness was related to metallurgical properties such as the microstructural and retained-austenite characteristics, and the strain-induced transformation behavior of the retained austenite.

\section{Experimental Procedure}

Vacuum-melted and hot-forged slabs were prepared with the chemical composition given in Table 1. These slabs were then hot-rolled to produce plates of $15 \mathrm{~mm}$ thickness and bars of $13 \mathrm{~mm}$ diameter. The martensite-start $\left(M_{\mathrm{s}}\right)$ and -finish $\left(M_{\mathrm{f}}\right)$ temperatures were respectively $401^{\circ} \mathrm{C}$ and $261^{\circ} \mathrm{C}$, where $M_{\mathrm{s}}$ and $M_{\mathrm{f}}$ were obtained from a dilatation curve at a cooling rate of $30^{\circ} \mathrm{C} / \mathrm{s} . M_{\mathrm{s}}$ was determined by the temperature at which the specimen was expanded by martensite transformation. $M_{\mathrm{f}}$ was determined by the temperature at which the expansion of specimen stopped. $\mathrm{Nb}$ was added to refine the prior austenitic grain. $\mathrm{Cr}$ was also added to improve the hardenability of the steel. For comparison, commercial SCM420 steel bars of $36 \mathrm{~mm}$ diameter were hot-rolled to make plates of $15 \mathrm{~mm}$ thickness and bars of 13 mm diameter.

Tensile specimens (JIS 14A: $5 \mathrm{~mm}$ diameter by $20 \mathrm{~mm}$ 
Table 1. Chemical composition (mass\%) and measured martensite-start $\left(M_{\mathrm{s}}\right)$ and -finish temperatures $\left(M_{\mathrm{f}},{ }^{\circ} \mathrm{C}\right)$ of steels used.

\begin{tabular}{l|cccccccccccccccc}
\hline \multicolumn{1}{c|}{ Steel } & $\mathrm{C}$ & $\mathrm{Si}$ & $\mathrm{Mn}$ & $\mathrm{P}$ & $\mathrm{S}$ & $\mathrm{Cu}$ & $\mathrm{Ni}$ & $\mathrm{Cr}$ & $\mathrm{Mo}$ & $\mathrm{Al}$ & $\mathrm{Nb}$ & $\mathrm{O}$ & $\mathrm{N}$ & $\mathrm{M}_{\mathrm{s}}$ & $\mathrm{M}_{\mathrm{f}}$ \\
\hline TRIP & 0.21 & 1.49 & 1.50 & 0.0019 & 0.004 & $<0.02$ & $<0.02$ & 1.00 & $<0.01$ & 0.040 & 0.050 & 0.0014 & 0.0013 & 401 & 261 \\
SCM420 & 0.21 & 0.21 & 0.77 & 0.0200 & 0.024 & 0.11 & 0.06 & 1.02 & 0.18 & $*$ & $*$ & $*$ & $*$ & $*$ & $*$ \\
\hline
\end{tabular}

*: not measured

(a)

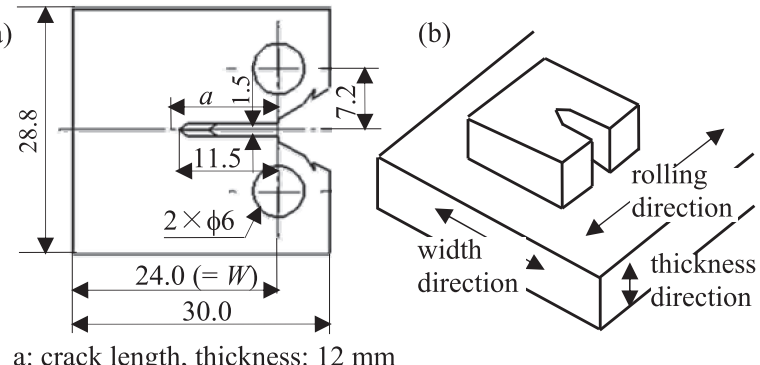

Fig. 1. (a) Dimensions and (b) machining directions of the compact specimen.

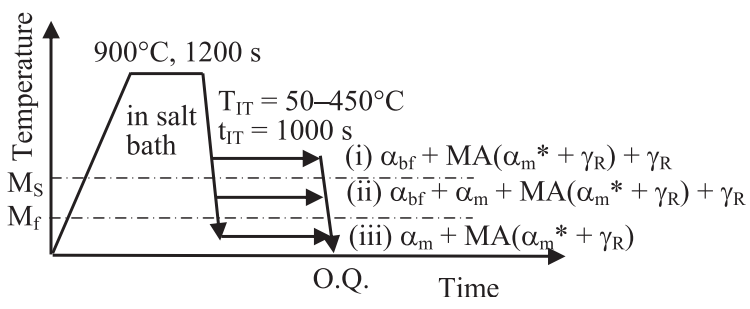

Fig. 2. Heat treatment diagram of TRIP-aided steel, in which $\alpha_{b f}$, $\alpha_{\mathrm{m}}, \alpha_{\mathrm{m}}{ }^{*}, \mathrm{MA}$, and $\gamma_{\mathrm{R}}$ denote bainitic ferrite, wide lath-martensite, narrow lath-martensite, MA-like phase, and retained austenite respectively.

gauge length) and compact specimens (ASTM-E399: 24 $\mathrm{mm}$ width and $12 \mathrm{~mm}$ thickness) were machined from these bars and plates, respectively (Fig. 1). The specimens were subjected to IT process at isothermal transformation temperature $\left(T_{\mathrm{IT}}\right)=50^{\circ} \mathrm{C}-450^{\circ} \mathrm{C}$ for isothermal transformation time $\left(t_{\mathrm{IT}}\right)=1000 \mathrm{~s}$ after austenitizing at $900^{\circ} \mathrm{C}$, as shown in Fig. 2.

The microstructure of the steels was observed by scanning electron microscopy (SEM), transmission electron microscopy (TEM) and field-emission-SEM/electron backscatter diffraction (EBSD) analysis. The volume fraction of retained austenite $\left(f_{\gamma}\right.$, vol\%) was calculated from the integrated intensity of the (200) $\alpha,(211) \alpha,(200) \gamma,(220) \gamma$ and (311)y peaks obtained by X-ray diffractometry using MoK $\alpha$ radiation. ${ }^{12)}$ The carbon concentration $(C \gamma, \operatorname{mass} \%)$ was estimated using Eq. (1). In this case, the lattice constant $\left(a_{\gamma}\right.$, units of $10^{-1} \mathrm{~nm}$ ) of retained austenite was calculated from the $(200) \gamma,(220) \gamma$ and $(311) \gamma$ peaks of $\mathrm{Cu}-\mathrm{K} \alpha$ radiation. ${ }^{13)}$

$$
\begin{aligned}
a_{\gamma} & =3.5780+0.0330 \% C_{\gamma}+0.00095 \% M n_{\gamma}-0.0002 \% N i_{\gamma} \\
& +0.0006 \% C r_{\gamma}+0.0220 \% N_{\gamma}+0.0056 \% A l_{\gamma} \\
& -0.0004 \% C o_{\gamma}+0.0015 \% C u_{\gamma}+0.0031 \% M o_{\gamma} \\
& +0.0051 \% N b_{\gamma}+0.0039 \% T i_{\gamma}+0.0018 \% V_{\gamma}+0.0018 \% W_{\gamma},
\end{aligned}
$$

where $\% M n_{\gamma}, \% N i_{\gamma}, \% C r_{\gamma}, \% N_{\gamma}, \% A l_{\gamma}, \% C o_{\gamma}, \% C u_{\gamma}, \% M o_{\gamma}$, $\% N b_{\gamma}, \% T_{i}, \% V_{\gamma}$ and $\% W_{\gamma}$ denote the concentrations of the respective individual elements (mass\%) in the retained aus-

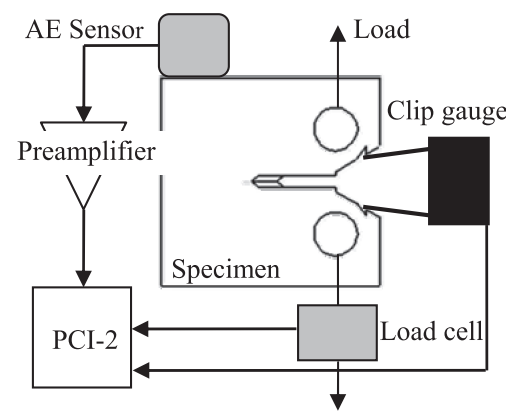

Fig. 3. Setup of the fracture toughness test.

tenite. As an approximation, the contents of added alloying elements were substituted for these concentrations in this study. The volume fraction of carbide in the specimens was measured as follows. First the specimens were etched in $5 \%$-nital etchant, and then carbon was coated on the specimen. Secondly, the carbon reprica with carbides was peeled off from the specimen in ethanol solution including $30 \%$ nitric acid, followed by TEM examination and image analysis in an area of about $560 \mu \mathrm{m}^{2}$.

Tensile tests were carried out on a tensile testing machine (Shimadzu Co., AG-10TD) at $25^{\circ} \mathrm{C}$ and a crosshead speed of $1 \mathrm{~mm} / \mathrm{min}$ (a strain rate of $8.33 \times 10^{-4} \mathrm{~s}^{-1}$ ). Fracture toughness tests were conducted on the same testing machine at $25^{\circ} \mathrm{C}$ using a clip gauge, after a pre-crack was introduced in a fatigue test according to ASTM and JSME standards. ${ }^{14,15)}$ Simultaneously, the AE technique was applied to detect a crack initiation signal and strain-induced transformation behavior of retained austenite using a PCI-2 system (PAC, USA). ${ }^{16)}$ The testing system is shown in Fig. 3. For this purpose, a wideband differential piezo-electric transducer (WD, $18 \mathrm{~mm}$ diameter) with an operating frequency range of $100-1000 \mathrm{kHz}$ was used. A wideband sensor was selected in preference to a resonant sensor because resonant sensors detect only a narrow band of frequencies. To ensure good coupling, lead break tests were performed before all tests using pencil leads with diameter of $0.5 \mathrm{~mm}$. The transducer was connected to a preamplifier with gain offset to 40 $\mathrm{dB}$. To remove noise from the actuator and other components, a threshold amplitude of $30 \mathrm{~dB}$ was selected after performing preliminary tests.

\section{Results}

\subsection{Microstructure and Tensile Properties}

Figure 4 shows SEM images of TRIP-aided steels isothermally transformed at temperatures between $50^{\circ} \mathrm{C}$ and $450^{\circ} \mathrm{C}$ and SCM420 steel tempered at $200^{\circ} \mathrm{C}$. EBSD analysis results of TRIP-aided steel are shown in Fig. 5. In Figs. 5(a) and 5(d), orange, yellowish green and black regions show the matrix structure, martensite-austenite complex phase and retained austenite, respectively. The volume frac- 

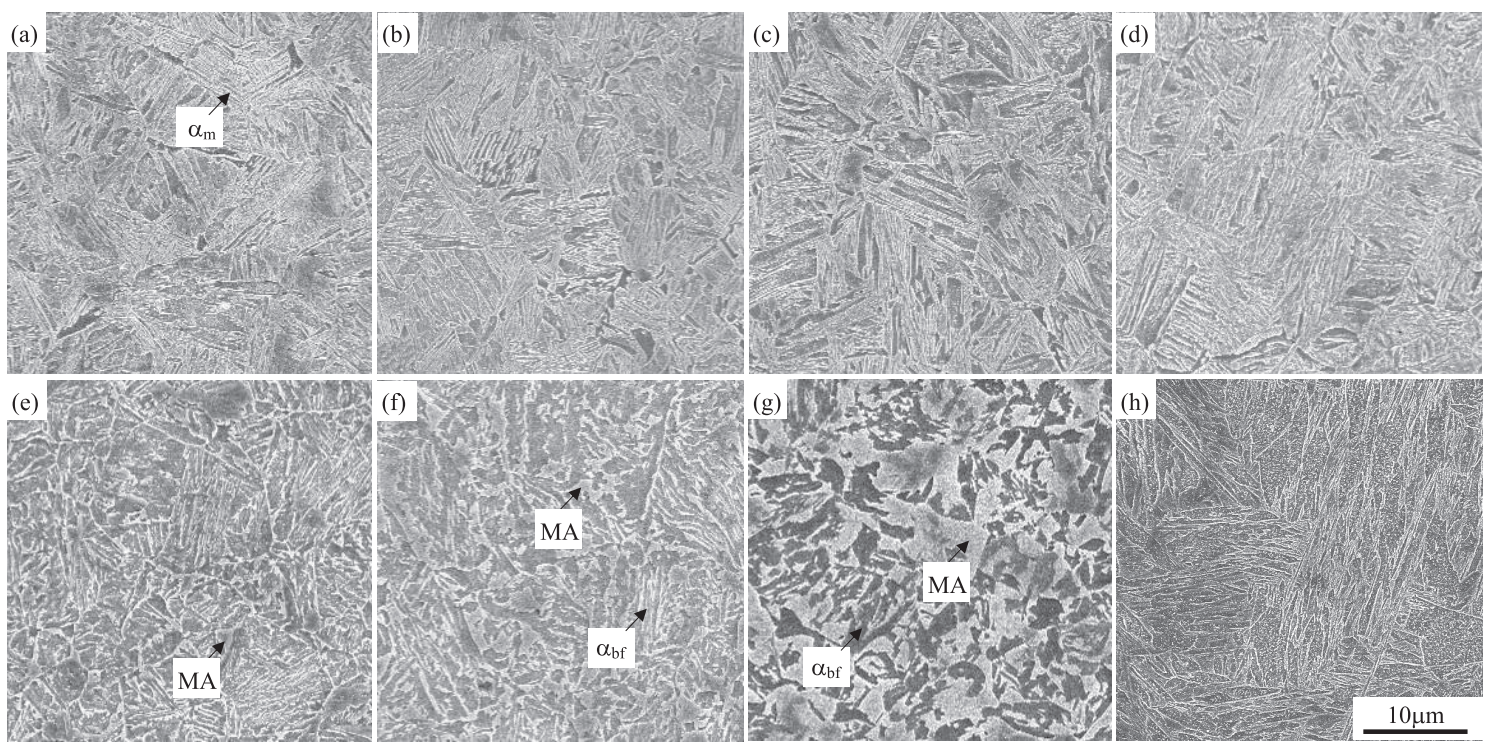

Fig. 4. SEM images of TRIP-aided steel subjected to IT process at (a) $T_{\mathrm{IT}}=50$, (b) 200, (c) 250, (d) 300, (e) 350, (f) 400 and (g) $450^{\circ} \mathrm{C}$ and (h) SCM420 steel tempered at $T_{\mathrm{T}}=200^{\circ} \mathrm{C}$, in which $\alpha_{\mathrm{bf}}, \alpha_{\mathrm{m}}$ and MA denote bainitic ferrite, martensite and MA-like phase, respectively.
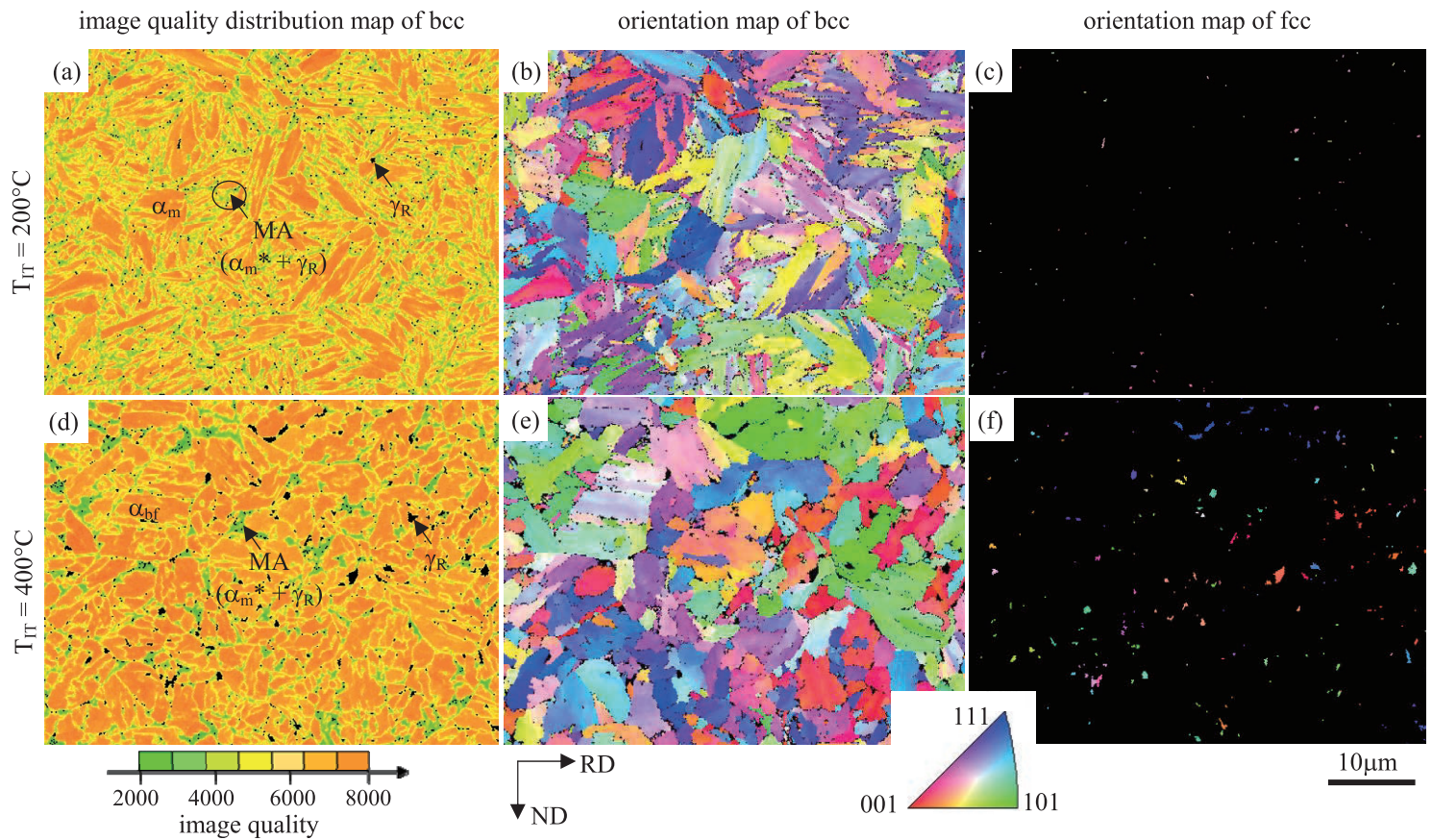

Fig. 5. Image quality distribution maps of body centered cubic lattice (bcc) and orientation maps of bcc and face centered cubic lattice (fcc) in TRIP-aided steel subjected to IT process at $T_{\mathrm{IT}}=200$ and $400^{\circ} \mathrm{C} . \alpha_{\mathrm{m}}, \alpha_{\mathrm{m}}{ }^{*}, \alpha_{\mathrm{bf}}, \mathrm{MA}$ and $\gamma_{\mathrm{R}}$ denote wide lath-martensite, narrow lath-martensite, bainitic ferrite, MA-like phase and retained austenite, respectively.

tion of blocky second phase was measured from the yellowish green region on image quality distribution map by EBSD analysis. In this study, it was assumed that the region of IQ index $<4675$ is blocky second phase. This yellowish green region was confirmed to be almost the same as the blocky second phase observed by SEM. Hereafter, the above complex phase is called the MA-like phase, because it resembles the MA constituent in conventional bainitic steel. When IT process was conducted at temperatures (i) higher than the $M_{\mathrm{S}}$ temperature $\left(401{ }^{\circ} \mathrm{C}\right)$, the microstructure of the TRIP-aided steel principally changed to bainitic ferrite, MA-like phase and isolated retained austenite as shown in Figs. 4(f), 4(g) and $5(\mathrm{~d})$. When IT process was carried out at temperatures (ii) between the $M_{\mathrm{s}}\left(401^{\circ} \mathrm{C}\right)$ and $M_{\mathrm{f}}\left(261^{\circ} \mathrm{C}\right)$ temperatures, the microstructure mainly consisted of bainitic ferrite, wide lath-martensite, finely dispersed MA-like phase and isolated retained austenite (Figs. 4(d) and 4(e)). In contrast, when IT process was carried out at temperatures (iii) below the $M_{\mathrm{f}}$ temperature $\left(261^{\circ} \mathrm{C}\right)$, the microstructure changed to wide lath-martensite and finely dispersed MA-like phase on prior austenitic grain, packet and martensite block boundaries (Figs. 4(a)-4(c) and 5(a)). The above results agree well with the previous studies ${ }^{2,3,9)}$ Thus hereafter, these TRIP-aided steels with microstructures obtained in cases (i), (ii) and (iii)

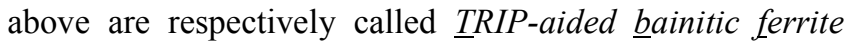
(TBF), TRIP-aided bainitic ferrite/martensitic (TBM) and 
Table 2. Retained austenite characteristics, tensile properties and fracture toughness of TRIP-aided and SCM420 steels.

\begin{tabular}{|c|c|c|c|c|c|c|c|c|c|c|c|c|c|c|c|c|}
\hline Steel & $\mathrm{T}_{\mathrm{IT}}$ & $f_{\gamma 0}$ & $\mathrm{C}_{\gamma 0}$ & $\mathrm{k}$ & $\mathrm{f}_{\mathrm{MA}}$ & $\mathrm{f}_{\theta}$ & YS & TS & YR & UEl & TEl & RA & $\mathrm{K}_{\text {in }}$ & $\mathrm{K}_{\mathrm{Q}}$ & $2.5 \mathrm{~K}_{\mathrm{Q}}^{2} / \mathrm{YS}^{2}$ & $\mathrm{~J}_{\mathrm{in}}\left(=\mathrm{J}_{\mathrm{IC}}\right)$ \\
\hline \multirow{7}{*}{ TRIP } & 50 & 3.4 & 0.76 & 1.31 & - & 1.39 & 1177 & 1599 & 0.73 & 5.2 & 13.5 & 53 & 82 & 86 & 13.3 & - \\
\hline & 200 & 5.6 & 0.30 & 4.99 & 18.0 & 0.85 & 1121 & 1518 & 0.74 & 5.2 & 16.1 & 66 & 121 & 129 & 33.1 & 0.090 \\
\hline & 250 & 6.4 & 0.42 & 5.50 & - & 0.62 & 1125 & 1486 & 0.76 & 5.9 & 16.6 & 65 & 139 & 141 & 39.2 & - \\
\hline & 300 & 5.2 & 0.73 & 3.43 & - & 0.43 & 1147 & 1431 & 0.80 & 4.4 & 15.3 & 68 & 146 & 154 & 45.1 & - \\
\hline & 350 & 8.6 & 0.85 & 3.61 & - & 0.24 & 1133 & 1405 & 0.81 & 5.0 & 16.4 & 68 & 136 & 144 & 40.4 & - \\
\hline & 400 & 14.2 & 0.61 & 2.90 & 14.8 & 0 & 857 & 1233 & 0.69 & 12.1 & 23.1 & 61 & 64 & 71 & 17.1 & - \\
\hline & 450 & 3.3 & 0.21 & 5.58 & 58.4 & 0 & 805 & 1357 & 0.59 & 8.9 & 16.9 & 41 & 48 & 54 & 11.2 & - \\
\hline \multirow[t]{2}{*}{ Steel } & $\mathrm{T}_{\mathrm{T}}$ & $\mathrm{f}_{\gamma 0}$ & $\mathrm{C}_{\gamma 0}$ & $\mathrm{k}$ & $\mathrm{f}_{\mathrm{MA}}$ & $\mathrm{f}_{\theta}$ & YS & $\mathrm{TS}$ & YR & UEl & TEl & RA & $\mathrm{K}_{\mathrm{in}}$ & $\mathrm{K}_{\mathrm{Q}}$ & $2.5 \mathrm{~K}_{\mathrm{Q}}^{2} / \mathrm{YS}^{2}$ & $\mathrm{~J}_{\mathrm{in}}\left(=\mathrm{J}_{\mathrm{IC}}\right)$ \\
\hline & 200 & 1.10 & - & - & 13.0 & 3.80 & 1291 & 1544 & 0.84 & 2.9 & 10.8 & 55 & 58 & 63 & 5.95 & 0.022 \\
\hline \multirow[t]{2}{*}{ SCM420 } & 300 & 0.31 & - & - & - & 5.14 & 1311 & 1469 & 0.89 & 2.5 & 10.2 & 46 & 46 & 57 & 4.72 & - \\
\hline & 400 & 0.00 & - & - & - & 5.41 & 1252 & 1310 & 0.96 & 2.3 & 10.0 & 46 & 83 & 94 & 14.1 & - \\
\hline
\end{tabular}

$T_{\mathrm{IT}}\left({ }^{\circ} \mathrm{C}\right)$ : isothermal transformation temperature, $T_{\mathrm{T}}\left({ }^{\circ} \mathrm{C}\right)$ : tempering temperature, $f_{\gamma 0}(\mathrm{vol} \%)$ : initial volume fraction of retained austenite, $C_{\gamma 0}($ mass $\%)$ : initial carbon concentration of retained austenite, $k$ : strain-induced transformation factor, $f_{\mathrm{MA}}$ : volume fraction of the MA-like phase, $f_{\theta}$ : volume fraction of carbide, $Y S$ (MPa): yield stress or $0.2 \%$ offset proof stress, $T S(\mathrm{MPa})$ : tensile strength, $Y R$ : yield ratio (=YS/TS), UEl (\%): uniform elongation, $T E l(\%)$ : total elongation, $R A$ $(\%)$ : reduction of area, $K_{\text {in }}\left(\mathrm{MPa} \mathrm{m}^{1 / 2}\right)$ : fracture toughness upon initial cracking, $K_{\mathrm{Q}}\left(\mathrm{MPa} \mathrm{m}^{1 / 2}\right)$ : provisional fracture toughness, $J_{\text {in }}(\mathrm{MPa}$ m): J-integral value upon crack initiation, $J_{\mathrm{IC}}(\mathrm{MPa} \mathrm{m})$ : J-integral value near the onset of stable crack extension.

TRIP-aided martensitic (TM) steels. SCM420 steel consisted of a wide lath-martensite structure and MA-like phase (Fig. 4(h)). However, the MA-like phase contained little retained austenite.

In the TBF and TBM steels, the retained austenite phases are mainly in the blocky MA-like phase or along the bainitic ferrite lath boundary (Fig. 5(d)). The volume fraction of martensite $\left(f \alpha_{\mathrm{m}}\right)$ increases with decreasing quenching temperature (in this study, quenching temperature is isothermal transformation temperature $\left(T_{\mathrm{IT}}\right)$ ) according to an equation reported by Koistinen and Marburger: ${ }^{17)}$

$$
f \alpha_{m}=1-\exp \left\{-1.1 \times 10^{-2}\left(M_{\mathrm{S}}-T_{\mathrm{IT}}\right)\right\},
$$

In this study, the volume fraction of wide lath-martensite in the TRIP-aided steel also increased with decreasing isothermal transformation temperature (Figs. 4 and 5). For the TRIP-aided steel, most of the MA-like phase is located on prior austenitic grain, packet and block boundaries. The MA-like phase fraction tends to be slightly higher in the TRIP-aided steel subjected to IT process at lower temperature, except for $T_{\mathrm{IT}}=450^{\circ} \mathrm{C}$ (Table 2). SEM-EBSD analysis showed that the SCM420 steel tempered at $200^{\circ} \mathrm{C}$ contained the same MA-like phase fraction as TRIP-aided steel, although most of the MA-like phase was formed only by the narrow lath-martensite structure.

Figure 6 shows TEM images of the TRIP-aided steels isothermally transformed at $200^{\circ} \mathrm{C}$ and $400^{\circ} \mathrm{C}$. When the steel was subjected to IT process at temperatures lower than $350^{\circ} \mathrm{C}$, a small amount of fine carbides precipitated in the wider lath-martensite structure (Fig. 6(a)). In contrast, there was no carbide in the steel subjected to IT process at $400^{\circ} \mathrm{C}$ and $450^{\circ} \mathrm{C}$. The amount of carbide increased with decreasing $T_{\mathrm{IT}}$, as shown in Table 2.

Figure 7 shows the retained-austenite characteristics of TRIP-aided steels isothermally transformed at temperatures between $50^{\circ} \mathrm{C}$ and $450^{\circ} \mathrm{C}$. The volume fraction of retained austenite in SCM420 steel is listed in Table 2. The volume fraction of retained austenite increases with increasing $T_{\mathrm{IT}}$, except for a sharp decrease at $450^{\circ} \mathrm{C}$. The variation in the
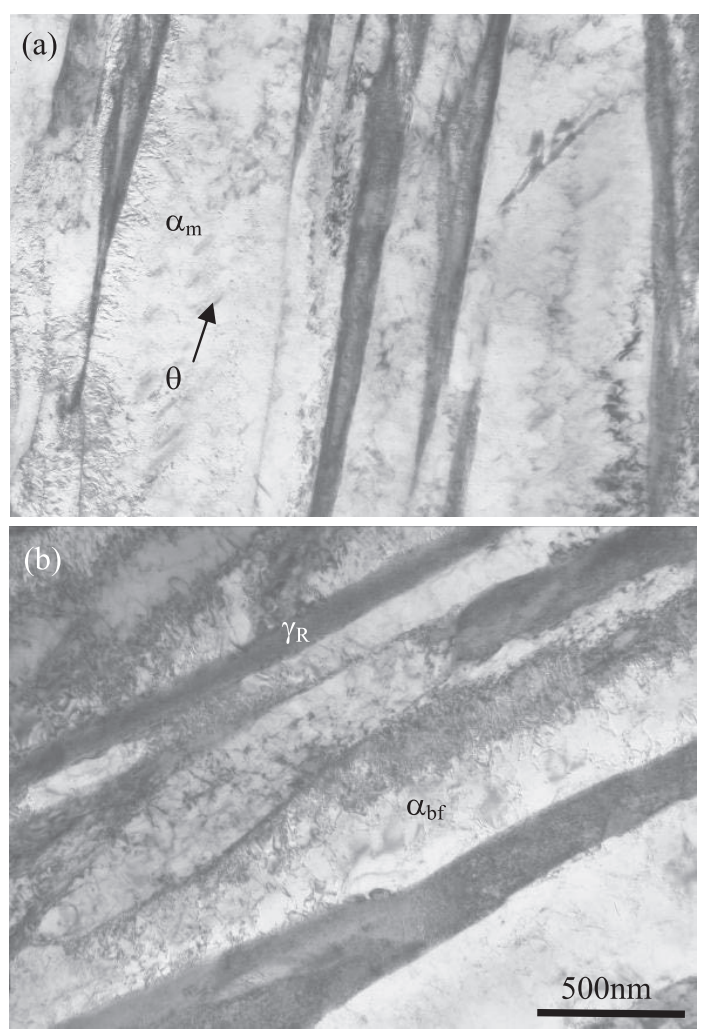

Fig. 6. TEM images of TRIP-aided steel subjected to IT process at (a) $T_{\mathrm{IT}}=200$ and (b) $400^{\circ} \mathrm{C}$, in which $\alpha_{\mathrm{m}}, \alpha_{\mathrm{bf}}, \gamma_{\mathrm{R}}$ and $\theta$ denote wide lath-martensite, bainitic ferrite, retained austenite and carbide, respectively.

carbon concentration is complex, with the minimum and maximum concentrations observed at $T_{\mathrm{IT}}=200^{\circ} \mathrm{C}$ and $350^{\circ} \mathrm{C}$, respectively.

Figure 7(b) shows the strain-induced transformation factor $k$ for TRIP-aided steel, defined by

$$
\log f_{\gamma}=\log f_{\gamma 0}-k \varepsilon
$$

where $f_{\gamma 0}$ and $f_{\gamma}$ are the volume fractions of retained austenite before and after straining to the plastic strain $\mathcal{E}$, respectively. 
In general, a lower $k$ value indicates higher mechanical stability of retained austenite and is related to a higher concentration of carbon in the retained austenite. ${ }^{1,2)}$ SCM420 steel tempered at $200^{\circ} \mathrm{C}$ contained only a little retained austenite $(1.10 \mathrm{vol} \%)$ in the MA-like phase, and the amount of

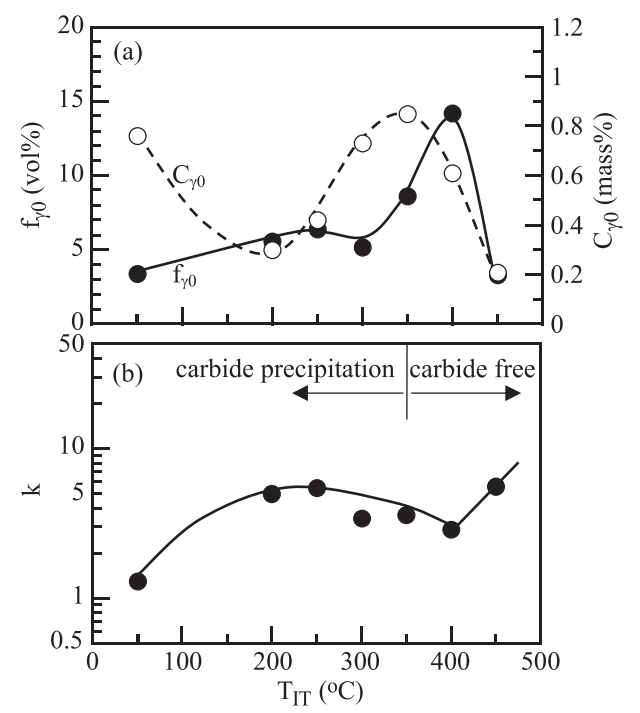

Fig. 7. Variations in (a) initial volume fraction $\left(f_{\gamma 0}\right)$ and carbon concentration $\left(C_{\gamma_{0}}\right)$ of retained austenite and (b) $k$ value as a function of isothermal transformation temperature $\left(T_{\mathrm{IT}}\right)$ in TRIP-aided steel.
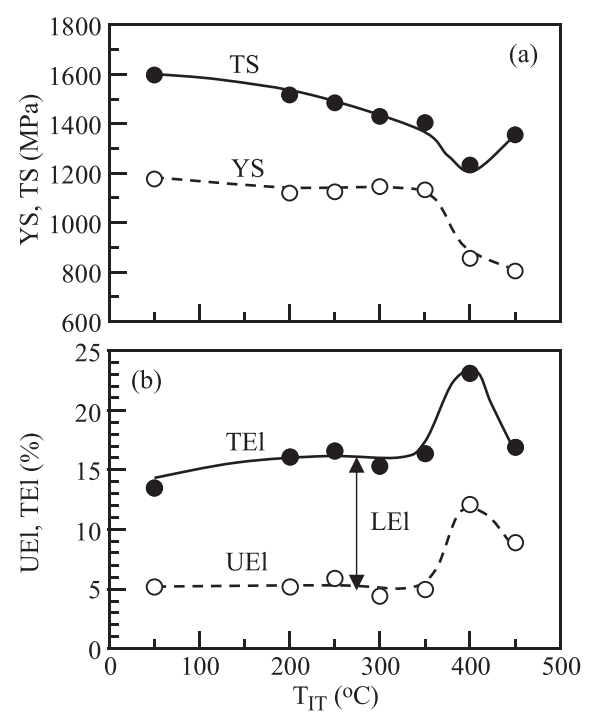

Fig. 8. Variations in (a) yield stress or $0.2 \%$ offset proof stress (YS) and tensile strength $(T S)$ and (b) uniform (UEl), local (LEl) and total elongations $(T E l)$ as a function of the isothermal transformation temperature $\left(T_{\mathrm{IT}}\right)$ in TRIP-aided steel. retained austenite considerably decreased with increasing tempering temperature (Table 2).

The tensile properties of the TRIP-aided steels are given in Table 2 and Fig. 8. If the steel is subjected to IT process at temperatures between $50^{\circ} \mathrm{C}$ and $350^{\circ} \mathrm{C}$, higher yield stress or $0.2 \%$ offset proof stress $(Y S=1121-1177 \mathrm{MPa})$ and tensile strength $(T S=1405-1599 \mathrm{MPa})$ are achieved. The tensile strength increases with decreasing $T_{\mathrm{IT}}$, although the yield stress is hardly affected by the $T_{\text {IT. }}$ When compared with SCM420 steel, the TRIP-aided steels have lower yield ratios and larger total elongations and greater reduction of areas (Table 2).

\subsection{Fracture Toughness}

Figure 9 shows load-displacement curves of TRIP-aided and SCM420 steels with AE signals. Both steels exhibited ductile fracture behavior. The maximum load and displacement to fracture of TRIP-aided steel isothermally transformed at $200^{\circ} \mathrm{C}$ are larger than those of TRIP-aided steel isothermally transformed at $400^{\circ} \mathrm{C}$ or SCM420 steel. AE signals in TRIP-aided steel originated before initial cracking, differing from the case for SCM420 steel, which means that some of the retained austenite was transformed by strain before initial cracking, which plastically relaxed the localized stress concentration around the crack tip.

Figure 10 shows the variation in provisional fracture toughness $\left(K_{\mathrm{Q}}\right)$ as a function of $T_{\mathrm{IT}}$ for the TRIP-aided steels. The provisional fracture toughness was calculated as $^{14)}$

$$
K_{\mathrm{Q}}=P_{\mathrm{Q}} f(\alpha) / B W^{1 / 2},
$$

where $f(\alpha)=29.6 \alpha^{1 / 2}-185.5 \alpha^{3 / 2}+655.7 \alpha^{5 / 2}-1017.0 \alpha^{7 / 2}+$ $638.8 \alpha^{9 / 2}$ and $\alpha=a / W$. Here $P_{\mathrm{Q}}$ is the provisional applied load and $a, B$ and $W$ are respectively the crack length, thickness and width of a compact specimen as seen in Fig. $1 . K_{\mathrm{Q}}$ values of the TRIP-aided steel isothermally transformed at $T_{\text {IT }}=200$ through $350^{\circ} \mathrm{C}$ are higher than values for steels subjected to IT process at other temperatures and nearly equal to the fracture toughness upon stable crack initiation $\left(K_{\text {in }}\right)$ calculated from AE (Table 2$)$. If both the following Eqs. (5) and (6) are satisfied, the calculated provisional fracture toughness $K_{\mathrm{Q}}$ can be evaluated as the plane-strain fracture toughness $K_{\mathrm{IC}}{ }^{14)}$

$$
P_{\max } / P_{\mathrm{Q}}<1.10
$$

$$
a, B>2.5 K_{\mathrm{Q}}^{2} / Y S^{2},
$$
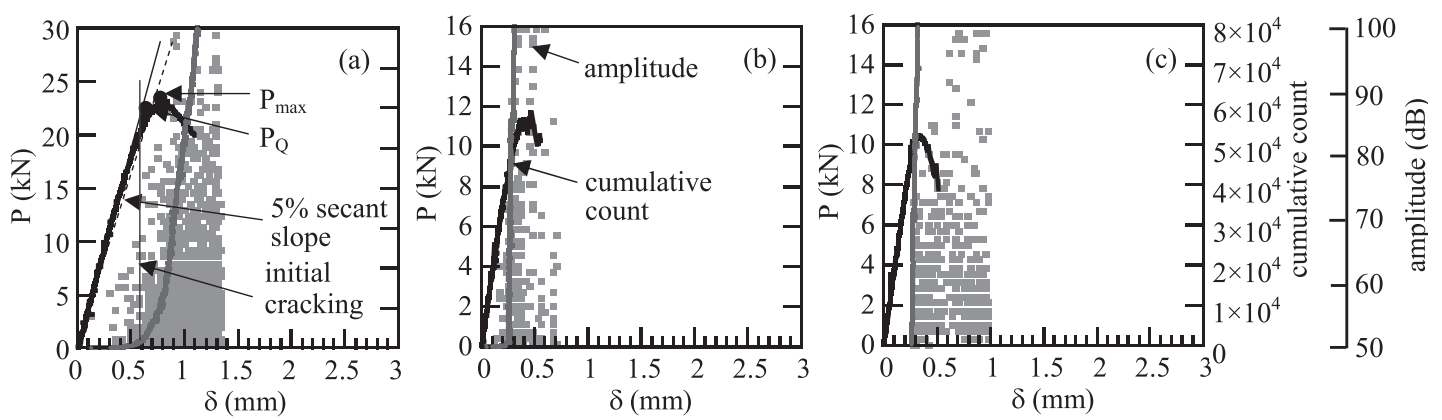

Fig. 9. Load-displacement $(P-\delta)$ curves and AE signals of TRIP-aided steel subjected to IT process at (a) $T_{\mathrm{IT}}=200$ and (b) $400^{\circ} \mathrm{C}$ and (c) SCM 420 steel tempered at $T_{\mathrm{T}}=200^{\circ} \mathrm{C}$. 
where $P_{\max }$ is the maximum load (see Fig. 9(a)). In this study, the specimen thickness $(B=12 \mathrm{~mm})$ of TRIP-aided steels subjected to IT process at $50^{\circ} \mathrm{C}-350^{\circ} \mathrm{C}$ was less than $B$ in Eq. (6), as for SCM420 steel tempered at $400^{\circ} \mathrm{C}$ (Table 2).

Figure 11 shows the blunting lines and R-curves of typical TRIP-aided and SCM420 steels. Since the J-integral value upon crack initiation $\left(J_{\text {in }}\right)$, which is determined from the intersection of the blunting line and R-curve, is satisfied by Eq. (7), $J_{\text {in }}$ can be considered equal to $J_{\mathrm{IC}}$ (the value of the J-integral near the onset of stable crack extension). ${ }^{15)}$

$$
B, b>25 J_{\text {in }} / \sigma_{\text {fs }},
$$

where $b$ is the length of the uncracked ligament of the specimen $(W-a)$ and $\sigma_{\mathrm{fs}}=(Y S+T S) / 2$.

When the plane-strain fracture toughness $K_{\mathrm{IC}}$ can be calculated by Eq. $(8),{ }^{15)}$ the estimated values of $K_{\mathrm{IC}}\left(137 \mathrm{MPa} \mathrm{m}^{1 / 2}\right.$

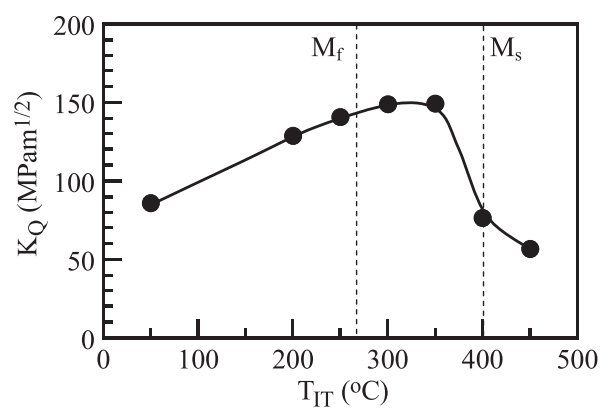

Fig. 10. Variation in fracture toughness $\left(K_{\mathrm{Q}}\right)$ as a function of the isothermal transformation temperature $\left(T_{\mathrm{IT}}\right)$ in TRIPaided steel.

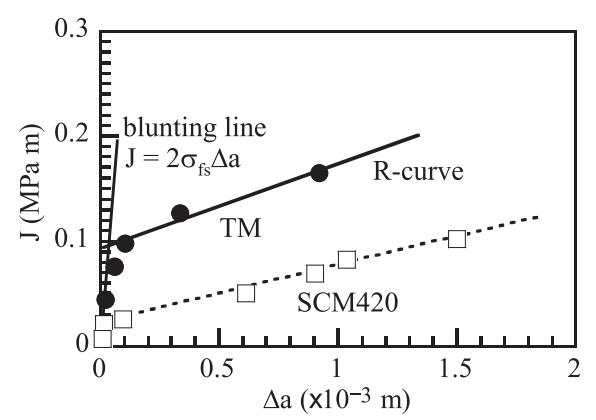

Fig. 11. Blunting line and R-curves of TRIP-aided steel subjected to IT process at $T_{\mathrm{IT}}=200^{\circ} \mathrm{C}$ and SCM420 steel tempered at $T_{\mathrm{T}}=200^{\circ} \mathrm{C}$, in which $\sigma_{\mathrm{fs}}=(Y S+T S) / 2$ and $\Delta a$ is the crack extension measured from the exposed fracture surface. for TRIP-aided steel, $67 \mathrm{MPa} \mathrm{m}^{1 / 2}$ for SCM420 steel) are nearly the same as the experimental values of $K_{\mathrm{Q}}$ (Table 2). Therefore, the $K_{\mathrm{Q}}$ values in Fig. 10 can be regarded as $K_{\mathrm{IC}}$ values.

$$
J_{\mathrm{IC}}=(1-v) K_{\mathrm{IC}}^{2} / E,
$$

where $v$ is Poisson's ratio $(0.28)$ and $E$ is Young's modulus (206 GPa).

Figure 12 shows the relationship between provisional fracture toughness $\left(K_{\mathrm{Q}}\right)$ and yield stress in TRIP-aided and SCM420 steels. The figure includes $K_{\mathrm{Q}}$ values of TRIP-aided steels subjected to IT process at $50{ }^{\circ} \mathrm{C}$ and subsequent partitioning process (heat treatment for carbon enrichment of retained austenite) at $50^{\circ} \mathrm{C}$ through $350{ }^{\circ} \mathrm{C}$ (ITP process), ${ }^{18)}$ and $K_{\mathrm{IC}}$ values of $18 \mathrm{Ni}$ maraging steel ${ }^{19,20)}$ and other steels. ${ }^{21)}$ Note that the present TRIP-aided steels subjected to IT process are characterized by the same level of fracture toughness as the maraging steel, although they exhibit much lower fracture toughness than the high-alloy TRIP steel.

Figure 13 shows SEM images of the fracture surfaces in the TRIP-aided and SCM420 steels. A distinct ductile fracture is seen only in the TRIP-aided steel subjected to IT process at $200^{\circ} \mathrm{C}-350^{\circ} \mathrm{C}$ (Fig. $13(\mathrm{a})$ ) and the SCM420 steel tempered at $200^{\circ} \mathrm{C}$ (Fig. 13 (c)). It is noteworthy that the former ductile fracture consists of fine and coarse dimples. In addition, the spacing between coarse dimples is $10-20 \mu \mathrm{m}$ and equivalent to that between larger MA-like phases. On the other hand, there was cleavage fracturing on the fracture surface of TRIP-aided steels subjected to IT process at $400^{\circ} \mathrm{C}$ and $450^{\circ} \mathrm{C}$ (Fig. 13(b)) and SCM420 steels tempered at $300^{\circ} \mathrm{C}$ and $400^{\circ} \mathrm{C}$ (Fig. $13(\mathrm{~d})$ ).

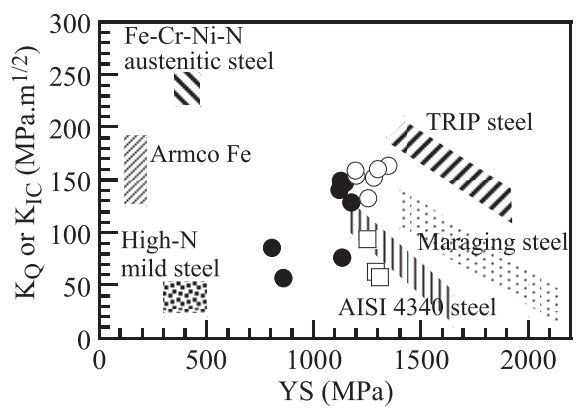

Fig. 12. Relationship between fracture toughness $\left(K_{\mathrm{Q}}\right.$ or $\left.K_{\mathrm{IC}}\right)$ and yield stress $(Y S)$ in TRIP-aided $(\bullet$ : IT process, ०: ITP process) ${ }^{18)}$ SCM420 (口), 18Ni maraging, ${ }^{19,20)} \mathrm{Fe}-\mathrm{C}-\mathrm{Cr}-\mathrm{Ni}-$ Mn TRIP, AISI4340 and other steels. ${ }^{21)}$

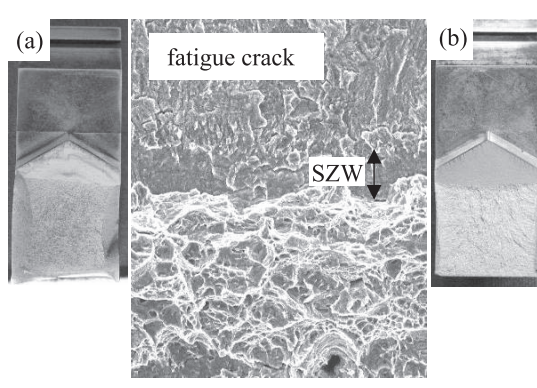

dimple fracture

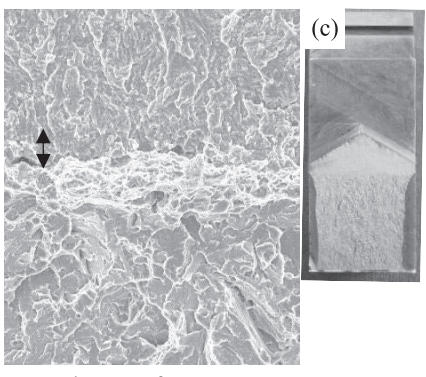

cleavage fracture

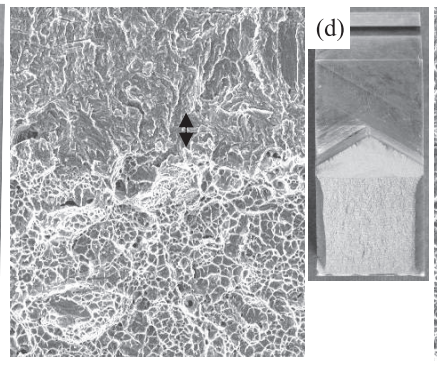

dimple fracture

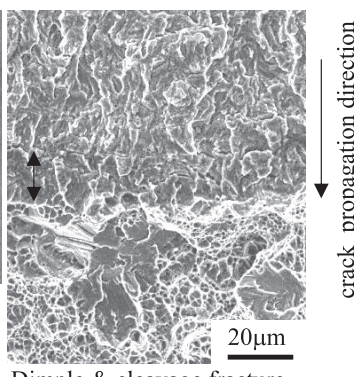

Dimple \& cleavage fracture

Fig. 13. SEM images of the fracture surface of TRIP-aided steel subjected to IT process at (a) $T_{\mathrm{TT}}=200$ and (b) $400^{\circ} \mathrm{C}$ and SCM420 steel tempered at (c) $T_{\mathrm{T}}=200$ and (d) $300^{\circ} \mathrm{C}$, in which SZW represents stretched zone width. 


\section{Discussion}

\subsection{Optimum Microstructure to Obtain High $K_{\mathbf{Q}}$}

In general, the fracture toughness of TRIP-aided steel is expected to be controlled in the same way as the impact toughness - by the matrix structure and characteristics of retained austenite (volume fraction, carbon concentration and morphology), the MA-like phase (morphology, volume fraction and site) and carbide fraction. ${ }^{9)}$ Figure 14 shows the relationships between $K_{\mathrm{Q}}$ and retained austenite characteristics in SCM420 steel tempered at $200^{\circ} \mathrm{C}, 300^{\circ} \mathrm{C}$ and $400^{\circ} \mathrm{C}$ and TRIP-aided steel subjected to IT process at temperatures between $50^{\circ} \mathrm{C}$ and $350^{\circ} \mathrm{C}$, where the carbon concentration of retained austenite in SCM420 steel was
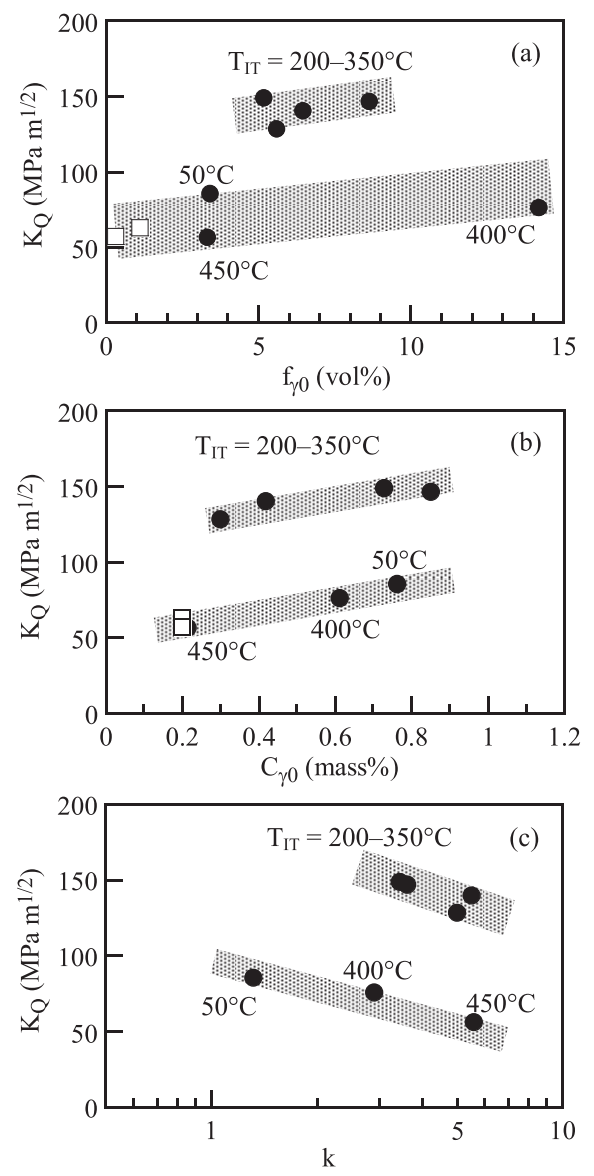

Fig. 14. Relationships between $K_{\mathrm{Q}}$ and (a) volume fraction $\left(f_{10}\right)$, (b) carbon concentration $\left(C_{\gamma_{0}}\right)$ and (c) strain-induced transformation factor $(k)$ of retained austenite in TRIPaided $(\bullet)$ and SCM420 steels (口). assumed to be 0.2 mass $\%$. From these results, we conclude that high $K_{\mathrm{Q}}$ values can be obtained with a high volume fraction, high carbon concentration and high stability of the retained austenite. The relationship between fracture toughness and $k$ in Fig. 14(c) agrees well with a report by Gerberich et $a{ }^{22)}$ that there is the following relationship between plane stress fracture toughness $K_{\mathrm{C}}$ and transformation coefficient $m$ for $\mathrm{C}-\mathrm{Cr}-\mathrm{Ni}-\mathrm{Mo}-\mathrm{Mn}-\mathrm{Si}$ system TRIP steels,

$$
K_{\mathrm{C}} \propto m^{1 / 2}
$$

where $m$ is related to the alloy stability in terms of the straininduced phase transformation, and is similar to $k$ in this study. It is known that high fracture toughness of maranging steel results from low carbon and high alloying matrix strengthened by fine precipitates. ${ }^{19,20,23)}$ If the maraging steel was subjected to over aging, a large amount of reverted austenite can be formed. In this case, the reverted austenite plays a role in further increasing fracture toughness, similar to the present TBM and TM steels.

When the TRIP-aided steel was isothermally produced at $400^{\circ} \mathrm{C}$ or $450^{\circ} \mathrm{C}, K_{\mathrm{Q}}$ decreased considerably. In Figs. 4(f), $5(\mathrm{~d})$ and 6(b), the matrix structure of the TRIP-aided steel isothermally transformed at $400^{\circ} \mathrm{C}$ was a coarse bainitic ferrite lath-structure. In addition, a large amount of blocky MA-like phase had formed, although a single phase of retained austenite was also present. Since the blocky MAlike phase is expected to behave like a stress concentration site, the low $K_{\mathrm{Q}}$ value of TRIP-aided steels may be due to a coarse matrix structure and blocky MA-like phase and a large difference in flow stress between the matrix and MAlike phase. On the other hand, higher $K_{\mathrm{Q}}$ values in the cases of $200^{\circ} \mathrm{C}-350^{\circ} \mathrm{C}$ are considered to be due to a fine mixture of wide lath-martensite and metastable retained austenite of about $5 \mathrm{vol} \%$ in the MA-like phase. In this case, the strength ratio of MA-like phase to matrix is relatively low, and void formation at the interface between MA-like phase and matrix is thus considerably suppressed, as opposed to the case at $400^{\circ} \mathrm{C}$ or $450^{\circ} \mathrm{C}$.

\subsection{Improvement Mechanism of $K_{Q}$}

In Fig. 13(a), a ductile fracture consisting of fine and coarse dimples appeared on the fracture surface of the TRIP-aided steel subjected to IT process at $200^{\circ} \mathrm{C}$, with a wide stretched zone width. Because the fracture is assumed to follow the Rice and Johnson model, ${ }^{24)}$ namely crack blunting, void initiation and growth, and void coalescence, the fracture behavior can be illustrated as shown in Fig. 15.

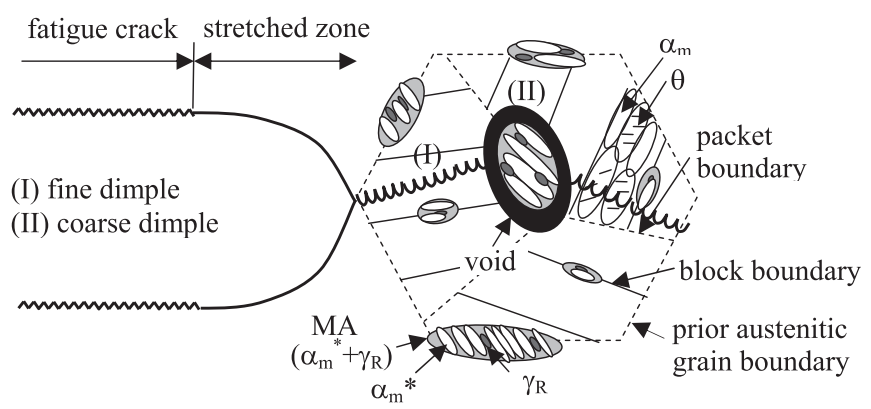

(1) Softened wide lath-martensite structure matrix

(2) Plastic relaxation of localized stress concentration by strain-induced transformation of metastable retained austenite $\square$

Suppression of void formation and stable crack extension

Fig. 15. Illustration of a ductile fracture consisting fine and coarse dimples in TRIP-aided steel subjected to IT process at $T_{\mathrm{IT}}=200^{\circ} \mathrm{C}$, in which $\alpha_{\mathrm{m}}, \alpha_{\mathrm{m}}{ }^{*}, \mathrm{MA}, \gamma_{\mathrm{R}}$ and $\theta$ denote wide lath-martensite, narrow lath-martensite, MA-like phase, retained austenite and carbide, respectively. 
In general, the initiation, growth and coalescence behavior of voids in bainitic or martensitic steels is controlled by interparticle paths of the second phases (MA-like phases) and carbides. According to Horn and Ritchie ${ }^{25)}$ and Sarikaya et al., ${ }^{26)}$ the carbide precipitates are located on the prior austenitic grain, packet, and block boundaries, as well as in the wide lath-martensite structure. These carbide precipitates generally act as void-initiation sites in martensitic steels. In the present TBM and TM steels, however, a small number of voids primarily initiate only at the larger MA-like phase/ wide lath-martensite structure matrix interface, not at matrix/carbide interface. At the larger MA-like phase/wide lath-martensite structure matrix interface at which there is a highly localized stress concentration results in, the voids then grow into the coarse dimples with the coalescence of the coarse voids and the forming of fine dimples (Fig. 15). In addition, the void formation is affected by the straininduced transformation of the retained austenite because some retained austenite phases are always included in the plastic region $\left(d_{\mathrm{Y}}\right)$ of the pre-crack tip estimated as ${ }^{27)}$

$$
d_{\mathrm{Y}}=K^{2} /\left(3 \pi Y S^{2}\right),
$$

where $K$ is a stress intensity factor defined as $\sigma(\pi c)^{1 / 2}, \sigma$ is the applied stress, and $c$ is the crack length. For steel isothermally produced at $200^{\circ} \mathrm{C}-350^{\circ} \mathrm{C}$, if $K$ and $Y S$ in Eq. (10) are $K_{\text {in }}$ and $Y S$ listed in Table $2, d_{\mathrm{Y}}$ is calculated as $1.2-1.7 \mathrm{~mm}$.

According to the work of Kobayashi et al. ${ }^{9)}$ on tensile deformation of TM steel, most voids are formed at the MAlike phase/matrix interface and the strain-induced transformation of the retained austenite in MA-like phase makes it difficult for voids to form because it relaxes plastically the localized stress concentration at the interface. Furthermore, it makes void coalescence or extension difficult because of the wide space between the large voids. The current TRIPaided steel isothermally produced at $200^{\circ} \mathrm{C}-350^{\circ} \mathrm{C}$ contained highly stable retained austenite and a large amount of finely dispersed MA-like phase, as well as a softened wide lath-martensite structure matrix containing little carbide. Therefore, it is considered that the void formation is primarily disturbed by (i) the plastic relaxation resulting from the strain-induced transformation of metastable-retained austenite and (ii) a softened wide lath-martensite structure matrix, as well as a small number of void initiation sites. These lead to higher fracture toughness through the difficulty of voids to coalesce compared with the case for SCM420 steel.

\section{Summary}

The fracture toughness of $0.2 \% \mathrm{C}-1.5 \% \mathrm{Si}-1.5 \% \mathrm{Mn}-$ $1.0 \% \mathrm{Cr}-0.05 \% \mathrm{Nb}$ ultrahigh-strength TRIP-aided steel with bainitic ferrite and/or martensite structure matrices was investigated to develop the next generation of structural steel. Important results are summarized as follows.

(1) When the TRIP-aided steel was isothermally transformed at temperatures between $200^{\circ} \mathrm{C}$ and $350^{\circ} \mathrm{C}$ below $M_{\mathrm{s}}$ after austenitizing, the steel had a tensile strength of $1.4 \mathrm{GPa}$ and total elongation of $15 \%$.

(2) The steel achieved a much higher fracture toughness (129-154 $\mathrm{MPa} \mathrm{m}^{1 / 2}$ ) than conventional structural SCM420 steel quenched and tempered at $200^{\circ} \mathrm{C}$ or $300^{\circ} \mathrm{C}(57-63$ $\mathrm{MPa} \mathrm{m}^{1 / 2}$ ). The fracture toughness was the same as that of maraging steel.

(3) It is considered that the superior fracture toughness is essentially due to (i) a softened wide lath-martensite matrix containing little carbide and (ii) effective plastic relaxation by the strain-induced transformation of fine metastable-retained austenite in the finely dispersed MA-like phase, which suppresses void formation, growth and coalescence as well as cleavage fracture at the pre-crack tip.

\section{Acknowledgment}

This study was supported by grants from the Adaptable and Seamless Technology Transfer Program through Targetdriven R\&D from the Japan Science and Technology Agency.

\section{REFERENCES}

1) K. Sugimoto, M. Murata and S. Song: ISIJ Int., 50 (2010), 162.

2) M. Murata, J. Kobayashi and K. Sugimoto: Tetsu-to-Hagané, 96 (2010), 84 (in Japanese).

3) J. Kobayashi, D. V. Pham and K. Sugimoto: Steel Res. Int. (Special Edition; ICTP 2011), 80 (2011), 598.

4) J. G. Speer, D. V. Edmonds, F. C. Rizzo and D. K. Matlock: Solid State Mater. Sci., 8 (2004), 219.

5) E. De Moor, J. G. Speer, D. K. Matlock, J.-H. Kwak and S.-B. Lee: Steel Res. Int., 83 (2012), 322.

6) T. Furukawa: Mater. Sci. Technol., 5 (1989), 465.

7) B. C. De Cooman, L. Chen, H. S. Kim, Y. Estrin, S. K. Kim and H. Voswinckel: Proc. of Int. Conf. on Microstructure and Texture in Steels and Other Materials, Springer, London, (2009), 165.

8) K. Sugimoto, D. Ina and J. Kobayashi: Proc. of ICAS 2010, Metall. Ind. Press, Beijing, (2010), 196.

9) J. Kobayashi, D. Ina and K. Sugimoto: Metall. Mater. Trans. A, 44A (2013), 5006.

10) N. Yoshikawa, J. Kobayashi and K. Sugimoto: Metall. Mater. Trans. $A, 43 \mathrm{~A}$ (2012), 4129.

11) J. Kobayashi, N. Yoshikawa and K. Sugimoto: ISIJ Int., 53 (2013), 1479.

12) H. Maruyama: J. Jpn. Soc. Heat Treat., 17 (1977), 198.

13) D. J. Dyson and B. Holmes: J. Iron Steel Inst., 208 (1970), 469.

14) ASTM Standard, E399-78, Standard Test Method for Plane-Strain Fracture Toughness of Metallic Materials, ASTM, West Conshohocken, PA, (1978).

15) JSME Standard, Standard Method of Test for Elastic-Plastic Fracture Toughness J JC, JSME S 001, JSME, Tokyo, (1981), 52.

16) M. Mukherjee, O. N. Mohanty, S. Hashimoto, T. Hojo and K. Sugimoto: ISIJ Int., 46 (2006), 1241.

17) D. P. Koistinen and R. E. Marburger: Acta Metall., 7 (1959), 59.

18) J. Kobayashi, D. Ina and K. Sugimoto: Proc. of MS\&T '12, TMS, Warrendale, PA, (2012), 937.

19) Y. He, K. Yang, W. Qu, F. Kong and G. Su: Mater. Lett., 56 (2002), 763.

20) Y. He, K. Yang and W. Sha: Metall. Mater. Trans. A, 36A (2005), 2273.

21) ASM Handbook, Vol.8, Mechanical Testing and Evaluation, ASM International, Materials Park, OH, (2007), 572.

22) W. W. Gerberich, P. L. Hemmings and V. F. Zackay: Metall. Trans., 2 (1971), 2243.

23) S. Floreen: Metall. Rev., 126 (1968), 115.

24) J. R. Rice and M. A. Johnson: Inelastic Behavior of Solids, ed. by M. F. Kanninen, McGraw-Hill Book Co., London, (1970), 641.

25) R. M. Horn and R. O. Ritchie: Metall. Trans. A, 9A (1978), 1039.

26) M. Sarikaya, A. K. Jhingan and G. Thomas: Metall. Trans. A, 14A (1983), 1121.

27) J. F. Knott: Fundamentals of Fracture Mechanics, Baifukan, Tokyo, (1977), 127. 